\title{
Experimental Investigation on the Performance of Different Cutting Fluids on Cutting Force During Turning of Duplex Stainless Steel-2205 under MQL Technique
}

\author{
Prashantha Kumar S.T. ${ }^{1}$, Thirtha Prasada H.P. ${ }^{2}$, Nagamadhu M. ${ }^{3 *}$, Niranjan Pattar ${ }^{4}$, S.B. Kivade ${ }^{5}$, Sachinkumar $^{6}$, \\ Ravichandra K.R. ${ }^{3}$, Hanumanthlal S. ${ }^{1}$ \\ ${ }^{1}$ Department of Mechanical Engineering, Vijaya Vittala Institute of Technology, Bengaluru 560077, Karnataka, India \\ ${ }^{2}$ Department of CAE, VTU PG Center, Bengaluru Region, Chickballapur 562103, Karnataka, India \\ ${ }^{3}$ Department of Mechanical Engineering, BMS Institute of Technology and Management, Bengaluru 560064, Karnataka, India \\ ${ }^{4}$ Department of Mechanical Engineering, KLE Dr. M S Sheshgiri College of Engineering and Technology, Belagavi 590008, \\ Karnataka, India \\ ${ }^{5}$ Department of Mechanical Engineering, Sri Jayachamarajendra College of Engineering (SJCE), Mysuru 570006, India \\ ${ }^{6}$ School of Mechanical Engineering, Reva University, Bengaluru 560064, Karnataka, India
}

Corresponding Author Email: nagamadhu74@gmail.com

https://doi.org/10.18280/mmep.090117

Received: 30 April 2020

Accepted: 7 December 2021

\section{Keywords:}

analysis of variance (ANOVA), deionized water, emulsified fluid, neat cut oil, minimum quantity lubrication $(M Q L), \quad$ response surface methodology (RSM)

\begin{abstract}
Duplex stainless steel (DSS)-2205 comes under hard-to-machine material owing to its inherent properties but more applications in severe working conditions. Hence, investigating the effect of cutting fluids and machining parameters is essential. In the present work, an attempt has been made with Minimum Quantity Lubrication (MQL) the investigate the performance of Deionized (DI) water, neat cut oil, and emulsified fluid on Cutting Force (CF) during turning of Duplex Stainless Steel (DSS-2205). The experiments were conducted based on face central composite design (CCF) in response surface methodology, varying speed, feed, and depth of cut in three levels. The Analysis of Variance (ANOVA) is to identify significant factors that influence the response. The results revealed that using emulsified fluid's cutting force gives better results than the DI water and neat cut oil. Feed rate is the most significant factor for emulsified fluid contribution was $53.61 \%$ for neat cut oil $48.89 \%$ and DI water $26.11 \%$. It also reveals that the contribution of the depth of cut is slightly lesser than the feed rate. However, the contributions of cutting speed in all three Deionized (DI) water, neat cut oil, and emulsified fluid working fluids are negligible.
\end{abstract}

\section{INTRODUCTION}

Machining is a vital process in manufacturing components to remove the material with the help of a cutting tool to get the final size and shape of the component. Several machining operations are turning, milling, grinding, and drilling. The various factors considered during turning operation include cutting speed, feed, depth of cut, cutting tool, workpiece material, type of the cutting fluid, and application of the cutting fluid. Kuram et al. [1] studied the applications of cutting fluid on the traditional method are not economical, and hence the Minimal Quantity Lubrication (MQL) has been gaining as an alternative solution for flood cooling. MQL is a technique in which the cutting fluid introduces into a chamber having high compressed air broken into small particles called aerosol. Aerosol is a mixture of fluid and air is applied in the cutting zone under high pressure in the form of a jet. Yusof et al. [2] worked on the MQL technique to prove that MQL has more benefits than dry machining. Nowadays, several cutting fluids are available for turning operations in industries such as natural oils, synthetic, mineral, and semi-synthetic oils. Mohd Saleem et al. [3] studied Mustard oil (vegetable oil) with MQL as an alternative cutting fluid while performing Turning operations on a Centre lathe machine using a single-point cutting tool of HSS compared with dry machining and other coolants. The results obtained indicate that vegetable oil performed a great cooling effect and lubrication similar to other coolants. Sathisha et al. [4] studied the effect of machining parameters like spindle speed, feed rate, and depth of cut under the dry and wet machining conditions during the turning of AISI 1018 steel. The experiment was conducted with dry and two types of cutting fluids, soluble oil and palm oil, to find tool tip temperature. Soluble oil gives better results compared with Palm oil. Kuram et al. [5-12] studied the three different vegetable-based cutting fluids refined sunflower oil and two commercial types (vegetable and mineral-based cutting oils) is used to determine for thrust force and surface roughness during drilling of AISI 304 austenitic stainless steel. The uses of vegetable cutting oils were investigated to reduce thrust force and improve surface finish at different spindle speeds and feed rates. Belluco and De Chiffre [13] Evaluated the performance of six cutting fluids (commercial mineral oil and five vegetable-based cutting fluids) in drilling AISI $316 \mathrm{~L}$ stainless steel. Tool life, tool wear, chip formation, and cutting forces were studied as performance criteria, and results were better with vegetable cutting oil than that of the mineral cutting fluid. Vishal Gandhe and Jadhav [14] studied the optimize the pressure $(\mathrm{P})$ and flow rate $(\mathrm{Q})$ of cutting fluid in an MQL system with a different type of cutting fluid to obtain improved machining performances in turning EN-8 steel. The results 
obtained indicate that neat oils with extreme pressure additives provide excellent lubrication and anti-weld properties over a wide range of temperatures. In day-to-day life, several verities of materials can be found for different applications, among one of these are Duplex Stainless Steels (DSS) have a mixed microstructure of austenite and ferrite. DSS has roughly twice the yield strength of austenitic stainless steels for their mixed microstructure provides improved resistance to chloride stress corrosion cracking compared to austenitic stainless steels. High work hardening rate, low thermal conductivity, high fracture toughness, strong tendency to form the built-up edge (BUE), and relatively high austenite and nitrogen content modern duplex stainless steels are regarded as poorly machinable materials [15, 16]. Selvaraj et al. [17] have optimized dry turning parameters of two different grades of nitrogen alloyed duplex stainless steel by using the Taguchi method. Their results revealed that the feed rate is the most significant parameter influencing the surface roughness and cutting force. Thiyagu et al. [18] studied dry machining of DSS material using RSM; the second-order response surface models for surface roughness and cutting force were developed to study the effect of machining parameters and tool geometry in turning. The results obtained indicate that feed rate and nose radius are significant factors in minimizing cutting force followed by cutting speed. Chauhan et al. [19-22] studied machining parameter cutting speed optimization, feed rate, depth of cut, and approach angle with surface roughness and tangential cutting force as response variables using Response surface methodology (RSM). The results obtained indicate that the surface roughness increases with the cutting speed and the feed rate, whereas tangential force increases with an increase in approach angle and depth of cut. The RSM is practical, economical, and relatively easy to use, and many researchers use it for modeling, analysis, and optimization of machining processes. RSM is a collection of mathematical and statistical techniques useful for the modeling and analyzing problems in which a dependent variable y called response is influenced by several independent variables $x_{1}, x_{2}, \ldots, x_{n}$ called factors, and the objective is to optimize the response [23-28]. Many researchers are very little work has been carried on the determination of optimum machining parameters on stainless steel materials and other materials under dry machining, and some researchers have used vegetable, soluble and mineral oils as cutting fluids; very little work has been done on turning of DSS in dry machining. In this study, turning tests were carried on DSS-2205 under MQL with three different cutting fluids and find out significant factors that affect the cutting force and suitable cutting fluid to reduce cutting force.

It is evident from the literature following literature gaps were identified.

$>\quad$ Very limited investigations were reported on the studies on cutting force under dry turning but not undercutting fluids.

$>\quad$ In the current work, investigate the performance of DI water, neat cut oil, and emulsified fluid during turning of duplex stainless steel-2205 on cutting force under MQL to identify significant process parameters affecting the response through ANOVA.

\section{EXPERIMENTAL DETAILS}

\subsection{Work piece material and cutting tool}

The material selected for the study was duplex stainless steel-2205 because it is difficult to cut materials. The machining of Duplex stainless steel-2205 is around 10-20\% slower than for other steel alloys. Table 1 shows the mechanical properties of the duplex stainless steel. The cutting tool used for experimentation was carbide coated insert TNMG 160404 MS PR-1535 Kyocera made with PVD multilayer coating.

\subsection{Cutting fluids}

Various fluids are used as cutting fluids for hard stainlesssteel materials in the industry. In the present work, Deionized water, neat cut oil, and Emulsified oil (1:20 concentration) were used. Base fluids are selected based on the literature survey and below properties (Table 2).

DI water: Selected based on their excellent wetting and spreading properties preferred where cooling is required, more comprehensive applications and low cost.

Neat cut oil: Selected based on their lubrication properties, suitable for stainless steel materials.

Emulsified fluid: Selected based on their superior properties, widely used in industrial machining application and low cost.

\subsection{Experimental conditions}

Experiments can be conducted based on Response Surface Methodology (RSM) face-centered Composite Factorial Design (CCF) is used. Twenty experiments were conducted with varying Speed, Feed, and Depth of Cut to measure output response of Cutting force for three cutting fluids the Table 5 shows the experimental order and cutting force values for different cutting fluids. The response surface design and analysis were performed using Design Expert-12 software.

\subsection{Experimental setup}

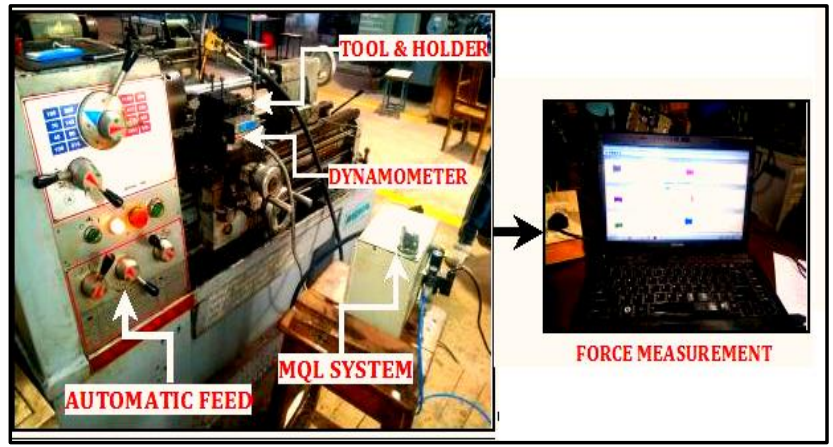

Figure 1. Experimental setup with MQL and dynamometer

Turning experiments were carried out using a MAGNUM1430 precision variable lathe machine. The three types of cutting fluids are used with three levels with varying speed, feed, and depth of cut to turning of DSS-2205 Table 3 shows the factors and level of experiments. Table 4 shows the machining environment to study the output behavior. The length of a work piece is $300 \mathrm{~mm}$, and the diameter is $40 \mathrm{~mm}$. The output parameter cutting force is measured using a lathe Kistler dynamometer, which is fixed to the lathe post, and forces are measured using DynoWare software. Figure 1 shows the experimental setup with MQL and dynamometer. 
Table 1. Mechanical properties of DSS-2205

\begin{tabular}{ccccc}
\hline Grade & Tensile Strength MPa & Yield Strength MPa & Elongation & Hardness BHN \\
\hline DSS-2205 & 620 & 450 & $>25$ & 234 \\
\hline
\end{tabular}

Table 2. Cutting fluids type and properties

\begin{tabular}{cccc}
\hline Base fluids & Density $\left(\mathbf{g} / \mathbf{c m}^{\mathbf{3}}\right)$ & Thermal Conductivity $(\mathbf{W} / \mathbf{m}-\mathbf{K})$ & Dynamic Viscosity (cP) \\
\hline DI water & 0.995 & 0.601 & 1.2 \\
Neat cut oil & 0.865 & 0.144 & 37 \\
Emulsified oil with DI water (1:20) & 0.996 & 0.527 & 1.4 \\
\hline
\end{tabular}

Table 3. Levels of experiments and factors

\begin{tabular}{cccc}
\hline Factors & Low level (-1) & Medium Level (0) & High Level (1) \\
\hline Cutting Speed $\mathrm{V}_{\mathrm{C}}(\mathrm{m} / \mathrm{min})$ & 50 & 70 & 90 \\
Feed $\mathrm{f}(\mathrm{mm} / \mathrm{rev})$ & 0.051 & 0.128 & 0.205 \\
Depth of cut d $(\mathrm{mm})$ & 0.4 & 0.8 & 1.2 \\
\hline
\end{tabular}

Table 4. Machining environment

\begin{tabular}{cc}
\hline Machining & Turning \\
\hline Work Piece Material & Duplex Stainless Steel-2205 \\
Tool Holder & Nice MTJNR1616H16 \\
Cutting Tool & TNMG-160404MS(PR1535) Coated Carbide \\
Flow rate & $10 \mathrm{ml} / \mathrm{min}$ \\
Type & $\mathrm{MQL}$ \\
\hline
\end{tabular}

Table 5. Experimental order and cutting force values for different cutting fluids

\begin{tabular}{ccccccc}
\hline \multirow{2}{*}{ Run No. } & Speed $\mathbf{~ m} / \mathbf{m i n}$ & \multirow{2}{*}{ Feed $\mathbf{~ m m} / \mathbf{r e v}$} & \multirow{2}{*}{ Depth of cut $(\mathbf{m m})$} & \multicolumn{3}{c}{ Cutting force (N) for different Cutting Fluids } \\
\cline { 5 - 6 } & & & DI water & Neat Cut oil & Emulsified Fluid \\
\hline 1 & 50 & 0.051 & 0.4 & 95 & 92 & 89 \\
2 & 50 & 0.051 & 1.2 & 269 & 252 & 205 \\
3 & 50 & 0.205 & 0.4 & 269 & 265 & 215 \\
4 & 50 & 0.205 & 1.2 & 620 & 610 & 580 \\
5 & 50 & 0.128 & 0.8 & 140 & 128 & 102 \\
6 & 90 & 0.128 & 0.8 & 335 & 278 & 228 \\
7 & 90 & 0.051 & 0.4 & 345 & 335 & 245 \\
8 & 90 & 0.051 & 1.2 & 780 & 660 & 645 \\
9 & 90 & 0.205 & 0.4 & 385 & 375 & 301 \\
10 & 90 & 0.205 & 1.2 & 530 & 430 & 403 \\
11 & 70 & 0.051 & 0.8 & 366 & 210 & 155 \\
12 & 70 & 0.205 & 0.8 & 638 & 489 & 420 \\
13 & 70 & 0.128 & 0.4 & 301 & 288 & 134 \\
14 & 70 & 0.128 & 1.2 & 584 & 498 & 390 \\
15 & 70 & 0.128 & 0.8 & 465 & 401 & 345 \\
16 & 70 & 0.128 & 0.8 & 462 & 391 & 328 \\
17 & 70 & 0.128 & 0.8 & 468 & 395 & 325 \\
18 & 70 & 0.128 & 0.8 & 470 & 399 & 345 \\
19 & 70 & 0.128 & 0.8 & 465 & 398 & 321 \\
20 & 70 & 0.128 & 0.8 & 463 & 399 & 348 \\
\hline
\end{tabular}

\section{RESULTS AND DISCUSSION}

Turning experiment was carried out using Response surface Methodology (RSM). Table 5 shows the order of the experiments with varying Speed, Feed and Depth of Cut with three levels and Cutting Force values for different cutting fluids.

Table 5 shows the Cutting force obtained for all base fluids turning, and Figure 2 shows the experimental run versus cutting force. From the results, the minimum value of cutting force obtained during all cutting parameters is low (-1), but increasing the cutting parameters to a higher level $(0$ and +1$)$ increases the cutting force. In the initial stage, the tool cutting edge is very sharp, and with low speed, low feed and low DOC, very less force is required to shear the material. This is observed all base fluids turning. When increasing the speed, feed, and DOC, the tool contact will be more with material leads to the formation of high friction between tool and work, tool and chip and increased wear of tool, the sharpness of the tool reduces and also strain hardening of the material leads to increasing the cutting force. The emulsified fluid (1:20 concentration with DI water) gives better results, followed by neat cut oil and DI water. The emulsified fluid is thicker than DI water; the oil content mixed with water has good flowability in the MQL nozzle compared to high viscous neat cut oil and produced the lubrication and cooling effect, 
reduced the friction between the tool and work, reduced wear rate of tool and also maintains the sharpness of the tool for a longer time due to that cutting force are reduces. The other base fluid, neat cut oil, has a high viscosity and less flowability through the MQL nozzle. It provides lubrication, but the low cooling effect increases the cutting force compared to the emulsified fluid. DI water has more flowability in the MQL nozzle. It gives a more cooling effect, but less lubrication for reducing friction during turning leads to the formation of a high wear rate of tool and high cutting forces compared to other fluids. The minimum cutting force value obtained was $89 \mathrm{~N}$ for emulsified fluid when all parameters were at a low level (-1), and the maximum force obtained was $780 \mathrm{~N}$ for DI water.

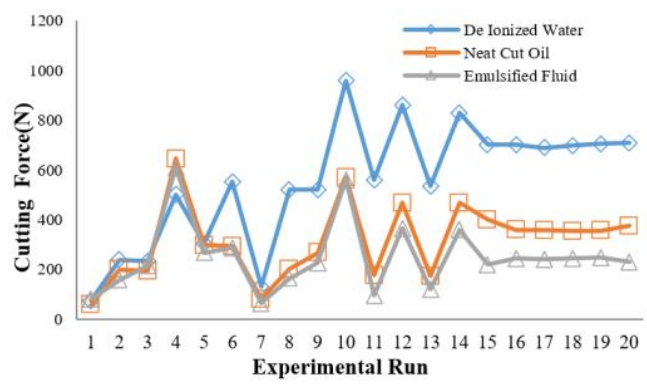

Figure 2. Actual cutting force values for different cutting fluids

\subsection{Analysis of variance (ANOVA) of cutting force for different cutting fluids}

Table 6 depicts the Anova for when DI water is used as a cutting fluid. The Prob> F is the probability of seeing the observed $F$ value if the null hypothesis is true (there is no factor effect). Small probability values call for rejection of the null hypothesis. In the present model, the F-value of 989.00 implies that the model is significant. There is only a $0.01 \%$ chance that an F-value this large could occur due to noise. Pvalues less than 0.0500 indicate that the model is significant. This model shows $\mathrm{A}, \mathrm{B}, \mathrm{C}, \mathrm{AB}, \mathrm{AC}, \mathrm{BC}, \mathrm{A}^{2}, \mathrm{C}^{2}$ are significant model terms. Table 7 shows the significance level of factors Depth of Cut is the most Significant Factor, followed by Feed and Cutting Speed when DI Water is used as a cutting fluid.

Table 8 depicts the Anova for when Neat Cut Oil is used as a cutting fluid. In the present model, the F-value of 71.81 implies the model is significant. There is only a $0.01 \%$ chance that an F-value this large could occur due to noise. P-values less than 0.0500 indicate model terms are significant. In this case, B, C, AC, BC, $\mathrm{A}^{2}$ are significant model terms. Table 9 shows that level of significance of factors Feed Rate is the most Significant Factor Followed by Depth of cut and Cutting Speed when Neat Cut Oil Used as a cutting fluid. Table 9 shows the ranking of input variables and found that feed rate (ranked I) and depth of cut (ranked II) influence significantly than speed.

Table 6. ANOVA for DI water cutting fluid

\begin{tabular}{|c|c|c|c|c|c|c|}
\hline Source & Sum of Squares & df & F-value & p-value & status & \% of Contri. \\
\hline Model & 1.141E+06 & 9 & 989.00 & 0.0001 & signi & \\
\hline A-Speed Vc & $1.766 \mathrm{E}+05$ & 1 & 1378.01 & 0.0001 & signi & 19.17 \\
\hline B-Feed f & $2.406 \mathrm{E}+05$ & 1 & 1876.83 & 0.0001 & signi & 26.11 \\
\hline C-Doc $\quad \mathrm{d}$ & $2.424 \mathrm{E}+05$ & 1 & 1891.38 & 0.0001 & signi & 26.31 \\
\hline $\mathrm{AB}$ & 20604.50 & 1 & 160.75 & 0.0001 & signi & 2.23 \\
\hline $\mathrm{AC}$ & 20000.00 & 1 & 156.04 & 0.0001 & signi & 2.17 \\
\hline $\mathrm{BC}$ & 2812.50 & 1 & 21.94 & 0.0009 & signi & 0.305 \\
\hline $\mathrm{A}^{2}$ & $2.162 \mathrm{E}+05$ & 1 & 1686.47 & 0.0001 & signi & 23.47 \\
\hline $\mathrm{C}^{2}$ & 1911.36 & 1 & 14.91 & 0.0032 & signi & 0.207 \\
\hline
\end{tabular}

Table 7. Level of significance of factors for DI water cutting fluid

\begin{tabular}{cccc}
\hline \multicolumn{5}{c}{ Level of Significance } \\
\hline-1 & A & B & C \\
1 & 262.75 & 241.5 & 240.25 \\
DIFF & 533.25 & 554.5 & 555.75 \\
RANK & 270.5 & 313 & 315.5 \\
& III & II & I \\
\hline
\end{tabular}

Table 8. ANOVA for Neat Cut oil cutting fluid

\begin{tabular}{ccccccc}
\hline Source & Sum of Squares & df & F-value & p-value & status & \% of Contri. \\
\hline Model & $\mathbf{4 . 3 4 6 E + 0 5}$ & $\mathbf{9}$ & $\mathbf{7 1 . 8 1}$ & $\mathbf{0 . 0 0 0 1}$ & signi & \\
A-Speed Vc & 32.40 & 1 & 0.0482 & 0.8307 & signi & 0.007 \\
B-Feed f & $2.031 E+05$ & 1 & 302.00 & 0.0001 & signi & 48.89 \\
C-Doc d & $1.706 E+05$ & 1 & 253.67 & 0.0001 & signi & 41.06 \\
AB & 84.50 & 1 & 0.1257 & 0.7303 & signi & 0.020 \\
AC & 3528.00 & 1 & 5.25 & 0.0450 & signi & 0.849 \\
BC & 30258.00 & 1 & 45.00 & 0.0001 & signi & 7.28 \\
A $^{2}$ & 5727.36 & 1 & 8.52 & 0.0153 & signi & 1.37 \\
C $^{2}$ & 1171.11 & 1 & 1.74 & 0.2163 & signi & 0.281 \\
\hline
\end{tabular}


Table 9. Level of significance of factors for Neat Cut oil cutting fluid

\begin{tabular}{|c|c|c|c|}
\hline \multicolumn{4}{|c|}{ LEVEL OF SIGNIFICANCE } \\
\hline & A & B & C \\
\hline-1 & 275 & 136 & 151.25 \\
\hline 1 & 280.5 & 419.5 & 404.25 \\
\hline DIFF & 5.5 & 283.5 & 253 \\
\hline RANK & III & I & II \\
\hline
\end{tabular}

Table 10. ANOVA for emulsified cutting fluid

\begin{tabular}{ccccccc}
\hline Source & Sum of Squares & df & F-value & p-value & status & \% of Contri. \\
\hline Model & $\mathbf{3 . 7 4 2 E + 0 5}$ & $\mathbf{9}$ & $\mathbf{1 8 8 . 2 0}$ & $\mathbf{0 . 0 0 0 1}$ & signi & \\
A-Speed Vc & 102.40 & 1 & 0.4635 & 0.5114 & signi & 0.027 \\
B-Feed f & $2.005 E+05$ & 1 & 907.59 & 0.0001 & signi & 53.61 \\
C-Doc d & $1.318 E+05$ & 1 & 596.55 & 0.0001 & signi & 35.02 \\
AB & 72.00 & 1 & 0.3259 & 0.5807 & signi & 0.019 \\
AC & 144.50 & 1 & 0.6541 & 0.4375 & signi & 0.038 \\
BC & 37538.00 & 1 & 169.92 & 0.0001 & signi & 10.03 \\
A $^{2}$ & 3403.84 & 1 & 15.41 & 0.0028 & signi & 0.910 \\
C $^{2}$ & 21.84 & 1 & 0.0989 & 0.7597 & signi & 0.005 \\
\hline
\end{tabular}

Table 11. Level of significance of factors for emulsified cutting fluid

\begin{tabular}{|c|c|c|c|}
\hline \multicolumn{4}{|c|}{ Level Of Significance } \\
\hline & $\mathbf{A}$ & B & C \\
\hline-1 & 266.25 & 117.5 & 147.25 \\
\hline 1 & 254.25 & 403 & 373.25 \\
\hline DIFF & 12 & 285.5 & 226 \\
\hline RANK & III & I & II \\
\hline
\end{tabular}

Table 10 depicts the Anova for when Emulsified Fluid used as a cutting fluid. In the present model, the F-value of 188.20 implies that the model is significant. There is only a $0.01 \%$ chance that an F-value this large could occur due to noise. $\mathbf{P}$ values less than 0.0500 indicate model terms are significant. In this case, $\mathrm{B}, \mathrm{C}, \mathrm{BC}, \mathrm{A}^{2}$ are significant model terms. Table 11 shows that level of significance of factors Feed Rate is the most Significant Factor Followed by Depth of cut and Cutting Speed when Emulsified Used as a cutting fluid. Table 11 shows the ranking of input variables and found that feed rate (ranked I) and depth of cut (ranked II) influence significantly than speed.

\subsection{Fit statistics for different cutting fluids}

Table 12. $\mathrm{R}^{2}$ values for different cutting fluids

\begin{tabular}{ccccc}
\hline $\begin{array}{c}\text { Type of } \\
\text { Fluid }\end{array}$ & $\mathbf{R}^{\mathbf{2}}$ & $\begin{array}{c}\text { Adjusted } \\
\mathbf{R}^{\mathbf{2}}\end{array}$ & $\begin{array}{c}\text { Predicted } \\
\mathbf{R}^{\mathbf{2}}\end{array}$ & $\begin{array}{c}\text { Adeq } \\
\text { Precision }\end{array}$ \\
\hline $\begin{array}{c}\text { DI Water } \\
\text { Neat Cut }\end{array}$ & 0.9989 & 0.9979 & 0.9878 & 110.8498 \\
$\begin{array}{c}\text { Oil } \\
\text { Emulsifie } \\
\text { d Fluid }\end{array}$ & 0.9848 & 0.9711 & 0.8510 & 32.4340 \\
\hline
\end{tabular}

The model Adequacies checked by analysis of variance technique. The $\mathrm{R}$ squared $\left(\mathrm{R}^{2}\right)$ correlation coefficient measures the variation proportion in the data points ranging from -1 to +1 . The value of $\mathrm{R}$ is close to 1 indicates that the model equation is significant. Table 12 shows the $\mathrm{R}^{2}$ values for all cutting fluids; the Predicted $\mathrm{R}^{2}$ is in reasonable agreement with the Adjusted $\mathrm{R}^{2}$. The difference is that 0.2 Adeq Precision measures the signal-to-noise ratio. A ratio greater than 4 is desirable. The ratio Adeq Precision indicates an adequate signal for all three models.

\subsection{Predicted and actual values}

Evaluate the predicted values using multiple linear regression coded equations and compare them with actual values in Table 13.

Table 13. Predicted and actual values for cutting force of different cutting fluids

\begin{tabular}{ccccccc}
\hline \multirow{2}{*}{$\begin{array}{c}\text { Run } \\
\text { no }\end{array}$} & \multicolumn{2}{c}{ DI Water } & \multicolumn{2}{c}{ Neat Cut Oil } & \multicolumn{2}{c}{ Emulsified Oil } \\
\cline { 2 - 7 } & $\begin{array}{c}\text { Palues } \\
\text { Vact }\end{array}$ & $\begin{array}{c}\text { Pre } \\
\text { Values }\end{array}$ & $\begin{array}{c}\text { Act } \\
\text { Values }\end{array}$ & $\begin{array}{c}\text { Pre } \\
\text { Values }\end{array}$ & $\begin{array}{c}\text { Act } \\
\text { Values }\end{array}$ & Values \\
\hline 1 & 106.8 & 95 & 97.1 & 92 & 95.5 & 89 \\
2 & 265.1 & 269 & 250.1 & 252 & 217.3 & 205 \\
3 & 261.7 & 269 & 272.4 & 265 & 229.9 & 215 \\
4 & 628.5 & 620 & 605.4 & 610 & 613.3 & 580 \\
5 & 138.5 & 140 & 130.0 & 128 & 142.1 & 102 \\
6 & 349.3 & 335 & 283.0 & 278 & 263.9 & 228 \\
7 & 355.9 & 345 & 334.3 & 335 & 276.5 & 245 \\
8 & 775.2 & 780 & 667.3 & 660 & 659.9 & 645 \\
9 & 382.2 & 385 & 376.2 & 375 & 341.3 & 301 \\
10 & 471.4 & 530 & 423.6 & 430 & 387.9 & 403 \\
11 & 330.1 & 366 & 205.5 & 210 & 194.3 & 155 \\
12 & 620.5 & 638 & 485.3 & 489 & 459.5 & 420 \\
13 & 264.4 & 301 & 262.9 & 288 & 148.3 & 134 \\
14 & 553.2 & 584 & 505.9 & 498 & 400.9 & 390 \\
15 & 475.3 & 465 & 399.9 & 401 & 326.9 & 345 \\
16 & 475.3 & 462 & 399.9 & 391 & 326.9 & 328 \\
17 & 475.3 & 468 & 399.9 & 395 & 326.9 & 325 \\
18 & 475.3 & 470 & 399.9 & 399 & 326.9 & 345 \\
19 & 475.3 & 465 & 399.9 & 398 & 326.9 & 321 \\
20 & 475.3 & 463 & 399.9 & 399 & 326.9 & 348 \\
\hline
\end{tabular}

Table 13 shows that the predicted values for different cutting fluids are calculated using Multilinear Regression Model equations, and the average \% error between Predicted versus Actual Values are acceptable. They were cutting force 
increases almost linearly with the increase in feed rate from $0.051 \mathrm{~mm} / \mathrm{rev}$ to $0.205 \mathrm{~mm} / \mathrm{rev}$ and depth of cut from $0.4 \mathrm{~mm}$ to $1.2 \mathrm{~mm}$.

Figures 3, $4 \& 5$ shows that Predicted versus Actual cutting force for different cutting fluids with DI water as cutting fluid the cutting force are maximum for all experimental runs followed by neat cut oil and emulsified fluid. It is clearly observed that emulsified fluid is better cutting fluid than Neat cut oil and DI water. It is also observed that the predicted value of neat cut oil is very much similar to actual, and error is very minimal compared to DI water and Emulsified Fluid. In the case of DI Water, the cutting force is more than neat cut oil and Emulsified Fluid. Form this; it clears that using Emulsified Fluid, the cutting force value can be reduced to a maximum extent compared to DI water and neat cut oil.

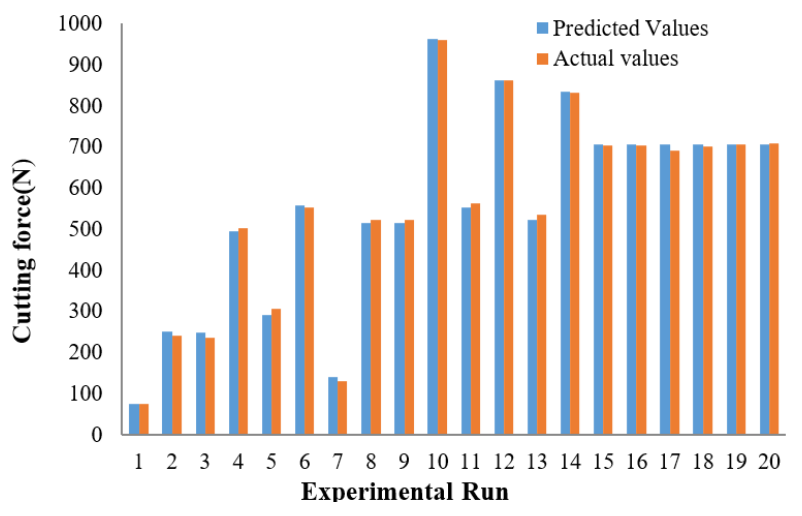

Figure 3. Predicted versus actual cutting force for deionized water

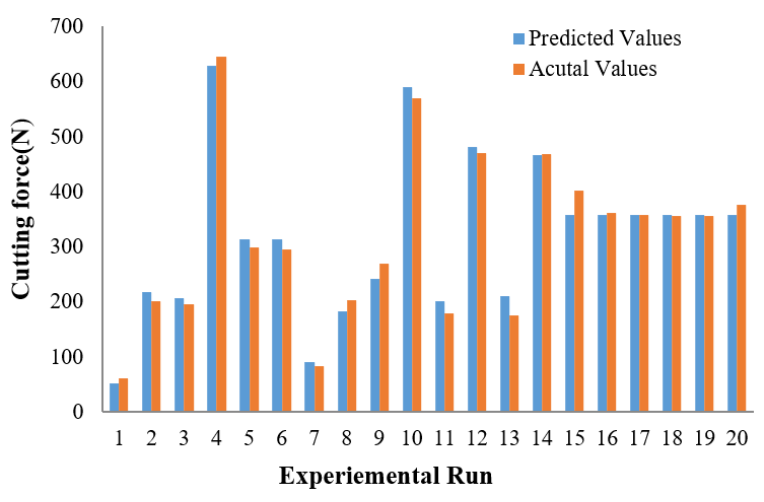

Figure 4. Predicted versus actual cutting force for neat cut oil

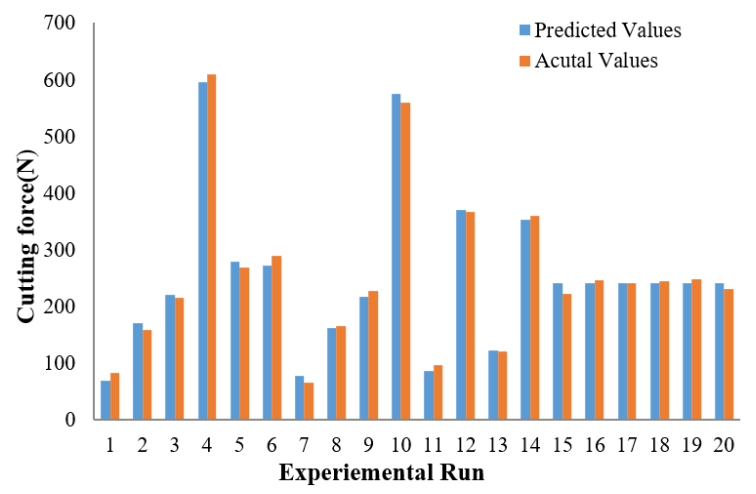

Figure 5. Predicted versus actual cutting force for emulsified fluid

\section{CONCLUSIONS}

The various machining factors to be considered while turning Duplex stainless steel-2205 like Cutting speed, feed, depth of cut, cutting fluid, and application of cutting fluid to the machining zone. These factors will be more effective on the machinability of the DSS-2205. This paper addressed with Application of Cutting Fluid through MQL and investigation the performance of Deionized water, neat cut oil, and Emulsified fluid on cutting force during turning of Duplex stainless steel (DSS-2205).

- The Analysis of variance (ANOVA) and significance level of factors for the Experimental Results revealed that the Feed rate is the most significant factor, followed by the depth of cut and cutting speed. Feed rate increases along with Depth of Cut Cutting Force also increases.

- The feed rate is the first most influential parameter on cutting force during turning of DSS-2205 with Emulsified fluid the feed contribution (53.61\%), Neat cut oil feed contribution $(48.89 \%)$, and DI water feed contribution $(26.11 \%)$.

- The Depth of Cut is the second influential parameter on cutting force during turning of DSS-2205 with Emulsified fluid the DOC contribution (35.02\%), Neat cut oil DOC contribution (41.06\%), and DI water DOC contribution $(26.31 \%)$.

- $\quad$ The cutting speed least significant input parameter, the percentage of contribution is $19.17 \%$ during DI water. However, it is minimal and negligible in other cutting fluids.

- $\quad$ Cutting force is a maximum of $780 \mathrm{~N}$ when all factors are high level with DI water fluid, and force is reduced to 645 $\mathrm{N}$ turning with Emulsified fluid for same factors.

- Overall results show that cutting force reduced during Emulsified fluid as cutting fluid followed by Neat cut oil and DI water.

\section{ACKNOWLEDGMENT}

We acknowledge the support rendered by the National Institute of Technology, Warangal-Telangana, India, for providing us an opportunity to conduct experimental work on the lathe and tool materials, measurement instruments, and all the necessary logistics as and when required.

\section{REFERENCES}

[1] Kuram, E., Ozcelik, B., Demirbas, E. (2013). Environmentally friendly machining: vegetable based cutting fluids. In Green Manufacturing Processes and Systems, pp. 23-47. https://doi.org/10.1007/978-3-64233792-5 2

[2] Yusof, M.Q.M., Harun, H.N.S.B., Bahar, R. (2018). Experimental investigation of minimum quantity lubrication in meso-scale milling with varying tool diameter. In IOP Conference Series: Materials Science and $\quad$ Engineering, 290(1): 012035. https://doi.org/10.1088/1757-899X/290/1/012035

[3] Saleem, M.S., Khan, M.Z., Zaka, M.Z. (2013). Vegetable oil as an alternate cutting fluid while performing turning operations on a lathe machine using single point cutting 
tool. International Journal of Technical Research and Applications, 1(5): 103-105.

[4] Sathisha, K.G., Lokesh, V., Priyesh, P. (2016). Effects of cutting fluids and machining parameter on turning of mild steel. In National Conference on Advances in Mechanical Engineering Science (NCAMES-2016), pp. 406-410.

[5] Kuram, E., Ozcelik, B., Demirbas, E., Sik, E. (2010). Effects of the cutting fluid types and cutting parameters on surface roughness and thrust force. In Proceedings of the World Congress on Engineering, pp. 978-988.

[6] Nagamadhu, M., Jeyaraj, P., Mohan Kumar, G.C. (2019). Mechanical and tribological behavior of woven sisal fabric. Tribology in Industry, 41(4): 622-633. https://doi.org/10.24874/ti.2019.41.04.14

[7] Jaiprakash, M., Nagamadhu, M., Karthikeyan, K. Kumar, G.M. (2020). Effect of drilling parameters on Neem wood veneer epoxy composites using grey relational analysis. Materials Today: Proceedings, 24(4): 2163-2173. https://doi.org/10.1016/j.matpr.2020.03.674

[8] Nagamadhu, M., Jaiprakash, M., Karthikeyan, K. (2020). Study the impact of drilling process parameters on natural fiber reinforced chaired epoxy composites. Materials Today: Proceedings, 24: 2204-2218. https://doi.org/10.1016/j.matpr.2020.03.678

[9] Nagamadhu, M., Jaiprakash, M., Karthikeyan, K. (2020). Effect of drilling process parameters on natural fiber reinforced basket epoxy composites using grey relational analysis. Materials Today: Proceedings, 24(4): $2255-$ 2264. https://doi.org/10.1016/j.matpr.2020.03.753

[10] Nagamadhu, M., Sehgal, S., Upadhya, R., Shankar, V.K., Hittinahalli, B. (2020). Mechanical and drilling process characterisation of herringbone sisal fabric reinforced vinyl ester sandwich composites. Advances in Materials and Processing Technologies, 6(2): 1-18. https://doi.org/10.1080/2374068X.2020.1855963

[11] Mahadevappa, N., Shankar, V.K., Sehgal, S., Upadhya, R. (2020). Study the impact of drilling process parameters on natural fiber reinforced herringbone epoxy composites. In Annales de Chimie-Science des Matériaux, 44(5): 339-345. https://doi.org/10.18280/acsm.440506

[12] Srinivas Rao, S., Arakalagudu Venkataramaiah, S., Mahadevappa, N. (2019). Optimization of drilling parameters of untreated JFRP PU foam sandwich by Taguchi method. Emerging Materials Research, 8(3): 434-443. https://doi.org/10.1680/jemmr.18.00055

[13] Belluco, W., De Chiffre, L. (2004). Performance evaluation of vegetable-based oils in drilling austenitic stainless steel. Journal of Materials Processing Technology, 148(2): 171-176 https://doi.org/10.1016/S0924-0136(03)00679-4

[14] Gandhe, V., Jadhav, V.S. (2013). Optimization of minimum quantity lubrication parameters in turning of EN-8 steel. International Journal of Engineering and Technical Research, 1(6): 11-14 https://www.academia.edu/download/32632874/IJETR0 11608.pdf.

[15] Koyee, R.D., Heisel, U., Schmauder, S., Eisseler, R. (2014). Experimental investigation and multiobjective optimization of turning duplex stainless steels. International Journal of Manufacturing Engineering, 2014: 921081. https://doi.org/10.1155/2014/921081

[16] Krolczyk, G., Legutko, S., Gajek, M. (2013). Predicting the surface roughness in the dry machining of duplex stainless steel (DSS). Metalurgija, 52(2): 259-262. https://hrcak.srce.hr/92683.

[17] Selvaraj, D.P., Chandramohan, P., Mohanraj, M. (2014). Optimization of surface roughness, cutting force and tool wear of nitrogen alloyed duplex stainless steel in a dry turning process using Taguchi method. Measurement, 49: 205-215.

https://doi.org/10.1016/j.measurement.2013.11.037

[18] Thiyagu, M., Karunamoorthy, L., Arunkumar, N. (2014). Experimental studies in machining duplex stainless steel using response surface methodology. International Journal of Mechanical \& Mechatronics Engineering, 14(3): 48-61.

[19] Chauhan, S., Dass, K. (2012). Optimization of machining parameters in turning of titanium (grade-5) alloy using response surface methodology. Materials and Manufacturing Processes, 27(5): 531-537. https://doi.org/10.1080/10426914.2011.593236

[20] Kumar, S.P., Thirthaprasada, H.P., Nagamadhu, M. (2020). Multi-response optimization of parameters in turning of DSS-2205 using hybrid $\left(\mathrm{Al}_{2} \mathrm{O}_{3}+\mathrm{CuO}\right)$ nano cutting fluid with MQL. Tribology in Industry, 42(4): 641-657. https://doi.org/10.24874/ti.894.05.20.11

[21] Karthikeyan, K., Nagamadhu, M., Jaiprakash, M., Kiran, Sheriff, M. (2020). Effect of drilling parameters on natural fiber reinforced with chaired epoxy poly urethane foam composites using grey relational analysis. Mater Today Proc, 24(4): 2193-2203.

[22] Prashantha Kumar, S.T., Thirtha Prasada, H.P., Nagamadhu, M., Siddarajud, C. (2021). Investigate the effect of $\mathrm{Al}_{2} \mathrm{O}_{3} \& \mathrm{CuO}$ nano cutting fluids under MQL technique in turning of DSS-2205. Advances in Materials and Processing Technologies. https://doi.org/10.1080/2374068X.2021.1948701

[23] Srikant, R.R., Prasad, M.M.S., Amrita, M., Sitaramaraju, A.V., Krishna, P.V. (2014). Nanofluids as a potential solution for minimum quantity lubrication: A review. Proceedings of the Institution of Mechanical Engineers, Part B: Journal of Engineering Manufacture, 228(1): 320. https://doi.org/10.1177\%2F0954405413497939

[24] Montgomery, D.C. (2010). Response surface methods and other approaches to process optimization. In Design and Analysis of Experiments, 5th edition, India WileyIndia, 427-448.

[25] Sonawane, G.D., Sargade, V.G. (2020). Machinability study of duplex stainless steel 2205 during dry turning. International Journal of Precision Engineering and Manufacturing, 21(5): https://doi.org/10.1007/s12541-019-00305-8

[26] Elmunafi, M.H.S., Mohd Yusof, N., Kurniawan, D. (2015). Effect of cutting speed and feed in turning hardened stainless steel using coated carbide cutting tool under minimum quantity lubrication using castor oil. Advances in Mechanical Engineering, 7(8). https://doi.org/10.1177/1687814015600666

[27] Khidhir, B.A., Mohamed, B. (2009). Selecting of cutting parameters from prediction model of cutting force for turning nickel based Hastelloy C-276 using response surface methodology. European Journal of Scientific Research, 33(3): 525-535.

[28] Reddy, N.S.K., Rao, P.V. (2006). Experimental investigation to study the effect of solid lubricants on cutting forces and surface quality in end milling. 
International Journal of Machine Tools and Manufacture, 46(2):

https://doi.org/10.1016/j.ijmachtools.2005.04.008

\section{NOMENCLATURE}

ANOVA Analysis of variance

CCF Central composite face centered
$\mathrm{CF}$

DOC

DOE

RSM

MQL

DI

DSS

cP
Fz cutting force (Newton)

Depth of cut

Design of experiments

Response surface methodology

Minimum quantity lubrication

De ionized

Duplex stainless steel

centipoise 